\title{
An Experimental Investigation on the Strength Properties of Self Curing Concrete by Using Super Absorbrnt Polymer
}

\author{
V. Veera Mohan Reddy ${ }^{1}$, K. Mohammed Rasheed ${ }^{2}$
}

${ }^{* 1}$ M.Tech, Department of Civil Engineering, Chiranjeevi Reddy Institution of Engineering and Technology, Anantapuram, Andhra Pradesh, India

${ }^{2}$ Assistant Professor, Department of Civil Engineering, Chiranjeevi Reddy Institute of Engineering and Technology, Anantapuram, Andhra Pradesh, India

\begin{abstract}
The super absorbent polymer (SAP) has the nature of absorbing large amount of water and converts into gel and at the same time it swells or a large amount of volume change occurs when SAP reacted with water. Main SAP agent is sodium polyacrylate. These properties are very useful and effective in plain concrete. It is proved that it has many positive effects on the properties of concrete in both stages; 1 .fresh concrete, 2 . hardened concrete. Super absorbent polymer is mainly having the water tightness properties of plain concrete with time. The study includes short term and long term effect of the super absorbent polymer on the water sealing properties. Many advantages exist in the use of super absorbent polymer in plain concrete with internal water. This internal water source acts as internal curing agent after the final setting of concrete. At the same time the SAP releases water at relatively slower rate at the fresh concrete stage. The SAP also provides additional voids in the concrete. These voids affect the concrete strength negatively at the same time improve the concrete performance by improving the concrete workability and consistency, reducing the concrete susceptibility to freezing thawing cycle, and improving concrete stability. In this project we tried to study the behavior of super absorbent polymer in mechanical properties of compression, split tensile and flexural strength with internally cured concrete. An experiment has been carried out for M50 concrete using Super absorbent polymer of $0 \%, 0.2 \%, 0.3 \%, 0.4 \%$ and $0.5 \%$ respectively. concrete cubes, cylinders and beams are casted and tested for 7 days and 28 days. The results are discussed in detailed and the compressive strength and split tensile strength greater for $0.2 \%$ of sap when compared with the remaining percentages of sap concrete. $0.2 \%$ of sap is optimum for the Beam of size 700X150X150 mm and shows the high flexural strength.
\end{abstract}

Keywords : Super Absorbent Polymer, Polyethylene Glycol, Hydration, Internal Curing, LWA

\section{INTRODUCTION}

\subsection{GENERAL}

The process of curing involves maintaining satisfactory moisture content and temperature after concrete is placed in order to hydrate the cement particles and produce the desired hardened concrete properties. Internal curing can be divided into two categories. The first category is internal water curing in which an internal curing agent stores water during mixing which is gradually released as hydration processes. The second category is internal sealing which is very similar to external sealed curing, in the goal of which is to prevent the loss of moisture from the concrete. 
The super absorbent polymer agent absorbs water and converts it into gel, then releases it slowly with time, at the same time the gel volume increases proportionally. The expansion in volume has the tendency to clog the water pathways in the concrete mass, and consequently improving its water tightness properties. The use of SAP is proven to be very effective as a sealant in plain concrete if sufficient amount is used. This paper focuses on the long-term effect as well as the short-term effect of the use of the SAP in plain concrete. Several samples such as sodium polyacrylate and polyethylene glycol were prepared with different SAP content. Generally, the content of SAP is measured as a percentage of the Portland cement used by weight. The amount of water added to the fresh concrete is one of the most important key factors that affect the concrete properties, including water tightness durability and strength. The water is an essential ingredient needed for the hydration process in the fresh concrete and for the curing process in the hardened concrete at its early stages. Excessive amount of water added in the fresh concrete improves the concrete workability in general, reduces the concrete strength, and increases the drying shrinkage of the hardened concrete. The most common admixture used nowadays is the superplastisizer which is water reducer and at the same time retarder. The water gel created in the fresh concrete by the use of SAP provides cushioning and lubrication in the concrete mass which in turn improves the concrete workability as well as the concrete stability.

The use of internal-curing admixtures is very important from the point of view that water resources are getting valuable every day (i.e., each 1 $\mathrm{m}^{3}$ of concrete requires about $3 \mathrm{~m}^{3}$ of water for constructio4n mostly for curing). The benefit of
Internal-curing admixtures is more significant in desert areas where water is not readily available.

\subsection{NEED FOR SELF-CURING}

When the mineral admixtures react completely in a blended cement system, their demand for curing water (external or internal) can be much greater than that in a conventional ordinary Portland cement concrete. When this water is not readily available, due to de-percolation of the capillary porosity. For example, significant auto-genius deformation and cracking may result.

Due to the chemical shrinkage occurring during cement hydration, empty pores are created within the cement paste, leading to a reduction in its internal relative humidity and also to shrinkage which may cause early-age cracking. This situation is intensified in HPC (compared to conventional concrete) due to its generally higher cement content, reduced water/cement (w/ c) ratio and the pozzolanic mineral admixtures (fly ash, silica fume). The empty pores created during self-desiccation induce shrinkage stresses and also influence the kinetics of cement hydration process, limiting the final degree of hydration. The strength achieved by internal curing could be more than that possible under saturated curing conditions.

Often specially in HPC, it is not easily possible to provide curing water from the top surface at the rate required to satisfy the ongoing chemical shrinkage, due to the extremely low permeability's often achieved.

\section{LITERATURE SURVEY}

\subsection{INTRODUCTION:}

Some of the early research works had done using different mineral admixtures for internal curing 
concrete. The literature pertaining to self curing concrete are reviewed and presented in this chapter.

\subsection{REVIEW OF LITERATURE ON SELF CURING CONCRETE}

Marianne Tange Hasholt, et al. [1] studied the effect of superabsorbent polymer on the mechanical strength of concrete by optimizing the dosage and internal water added. The authors arrived at the conclusion that "Addition of SAP does not lead to decrease in mechanical strength and while one has to be very patient and careful, it is possible to not only retain the same strength but also to increase it while preventing self-dessication.

M. Manoj Kumar, et al. [2] studied the effects of addition of using different ratios of superabsorbent polymer on the various mechanical properties of concrete, like Compressive Strength, Splitting Tensile Strength and Flexural Strength and compared them to conventional concrete.

Vivek Hareendran, et al.[3] created five different mixes of self- curing concrete and testd them with conventional self cured concrete for mechanical properties of concrete like Compressive Strength, Splitting Tensile Strength and Flexural Strength.

Moayyad Al-Nasra, et al. [4] studied the effect on superabsorbent polymer on fresh and hardened concrete using sodium polyacrylate and conducted some tests on the strength and stability of internally cured concrete.

M. KhodadadSaryazdi et al. [5] Self-desiccation is the major source of autogenous shrinkage and crack formation in low water-binder ratio (w/b) concreteswhich can be reduced by internal curing. In this paper performance of high strength self consolidating concrete (HS-SCC) withw/b of 0.28 and
0.33 including autogenous shrinkage, drying shrinkage, compressive strength, and resistance to freezing-thawingwas investigated. Then, for the purpose of internal curing, 25\% of normal weight coarse aggregate volume was replaced withsaturated lightweight aggregate (LWA) of the same size; and its effects on the material properties was studied. Two modes ofexternal curing, moist and sealed, were applied to test specimens after demoulding. Autogenous shrinkage from 30 minutes to 24hours after mixing was monitored continuously by a laser system. The initial and final setting time were manifested as a changeof the slope of the obtained deformation curves. Shrinkage after initial setting was 860 and 685 microstrain $(\mu \varepsilon)$ for 0.28 and $0.33 \mathrm{w} / \mathrm{b}$ mixtures, respectively. The saturated LWA reduced these values to 80 and $295 \mu \varepsilon$, respectively. By LWA Substitution the 28-day compressive strength of $0.28 \mathrm{w} / \mathrm{b}$ mixture was reduced from 108 to 89 and 98 to $87 \mathrm{MPa}$ for moist and sealed cured specimen,respectively. The corresponding values for $0.33 \mathrm{w} / \mathrm{b}$ mixture was 84 to 80 and 82 to $70 \mathrm{MPa}$. Shrinkage of $0.28 \mathrm{w} / \mathrm{b}$ mixture without LWA after moist and sealed cured specimen dried for 3 weeks was about $400 \mu \varepsilon$. Shrinkage of moist and sealed cured specimen containing LWA was reduced 9\% and $25 \%$, respectively. On the contrary for $0.33 \mathrm{w} / \mathrm{b}$ mixture an increase was noticed. Freezing-thawing resistance was improved by sealed curing, decreasing $\mathrm{w} / \mathrm{b}$ and substituting LWA.

\section{METERIAL PROPERTIES}

The materials used for this experimental study were deeply analysed and quality measures were taken in proper execution .The project consumes materials which are inert and available easily in abundance thus making it cost efficient with the calibre to withstand the constructional challenges faced in curing process. 


\subsubsection{Materials Used}

\section{Cement}

Cement used in the investigation was 53 grade ordinary Portland cement confirming IS: 12269: 1987.

\section{Fine aggregate}

River sand passing through $4.75 \mathrm{~mm}$ sieve is used.

\section{Coarse aggregate}

Coarse aggregate is naturally found rock particles which can be taken by crushing them. Various sizes of aggregates are available such as $20 \mathrm{~mm}, 40 \mathrm{~mm}$.

\section{Silica fume}

The silica fume used in this project is densified.

\section{Chemical admixtures}

The chemical admixture used is superplasticising admixture.

\section{ADMIXTURES FOR IC}

Sodium poly acrylate as a Super absorbent polymer is used as admixture for internal curing.

\section{Water}

A tap water available in the concrete laboratory was used in casting process.

Super absorbent polymer Properties

\subsection{SUPER ABSORBENT POLYMER}

Superabsorbent polymer (SAP) is a polymeric material which is able to absorb a significant amount of water from the surroundings and to retain the liquid within its structure without dissolving it takes up water during the mixing process, so it can be used as a dry concrete admixture and the use of SAP permits free design of the shape and size of the formed inclusions. The super absorbent polymer used in this study is Sodium Polyacrylate, also known as water-lock, which is a sodium salt of polyacrylic acid with the chemical formula [-CH2- $\mathrm{CH}(\mathrm{COONa})-] \mathrm{n}$ and broad application in consumer products. It has the ability to absorb as much as 200 to 300 times of its mass in water. The maximum water absorption is approximately 5000 times its weight. Sodium polyacrylate is anionic polyelectrolyte with negatively charged carboxylic group in the main chain. Below figure, shows the composition of the sodium polyacrylate.

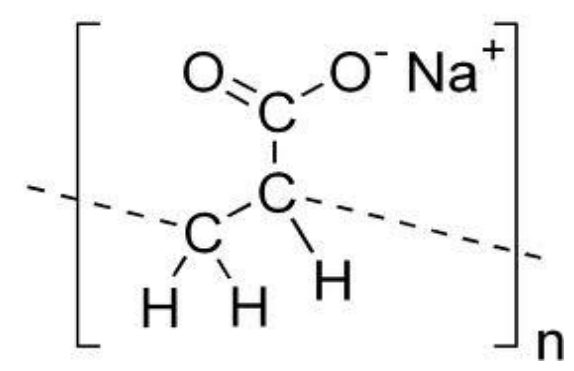

Sodium polyacrylate is a chemical polymer it is made up of multiple chains of acrylate compounds that possess a positive anionic charge, which attracts water-based molecules to combine with it, making sodium polyacrylate a super-absorbent compound. Sodium polyacrylate is used extensively in the agricultural industry and is infused in the soil of many potted plants to help them retain moisture, behaving as a type of water reservoir. Florists commonly use sodium polyacrylate to help keep flowers fresh. 


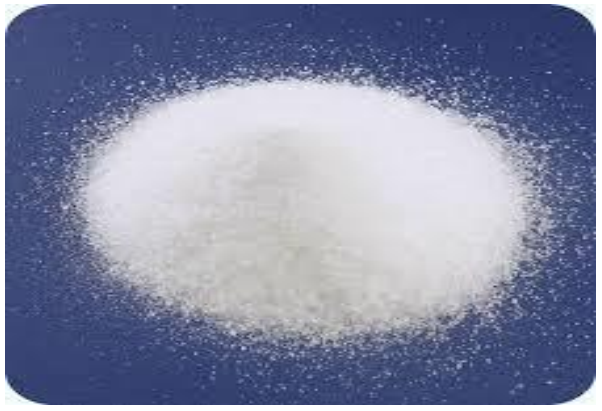

IV. EXPERIMENTAL WORK AND TESTING

\subsection{GENERAL}

Preliminary tests are done to determine the characteristics of the aggregates to be used in preparation of concrete before mixing to know about the materials and how to use it.

\subsection{Tests to be done in these work are given below:}

- Specific gravity test.

- Water absorption test.

- Sieve analysis.

\subsection{SPECIFIC GRAVITY}

Specific gravity is the ratio of the density of a substance to the density of a reference substance; equivalently, it is the ratio of the mass of a substance to the mass of a reference substance for the same given volume. Specific gravity of fine aggregate and coarse aggregate is measured by pycnometer and Digital density meters.

In this process, we are using pycnometer for measuring the specific gravity of aggregates. A pycnometer is simply a bottle which can be precisely filled to a specific, but not necessarily accurately known volume. Placed upon a balance of some sort it will exert a force. A pycnometer is usually made of glass, with a close-fitting ground glass stopper with a capillary tube through it, so that air bubbles may escape from the apparatus.
The pycnometer is used in ISO standard: ISO 11831:2004, ISO 1014-1985 and ASTM standard: ASTM D854.
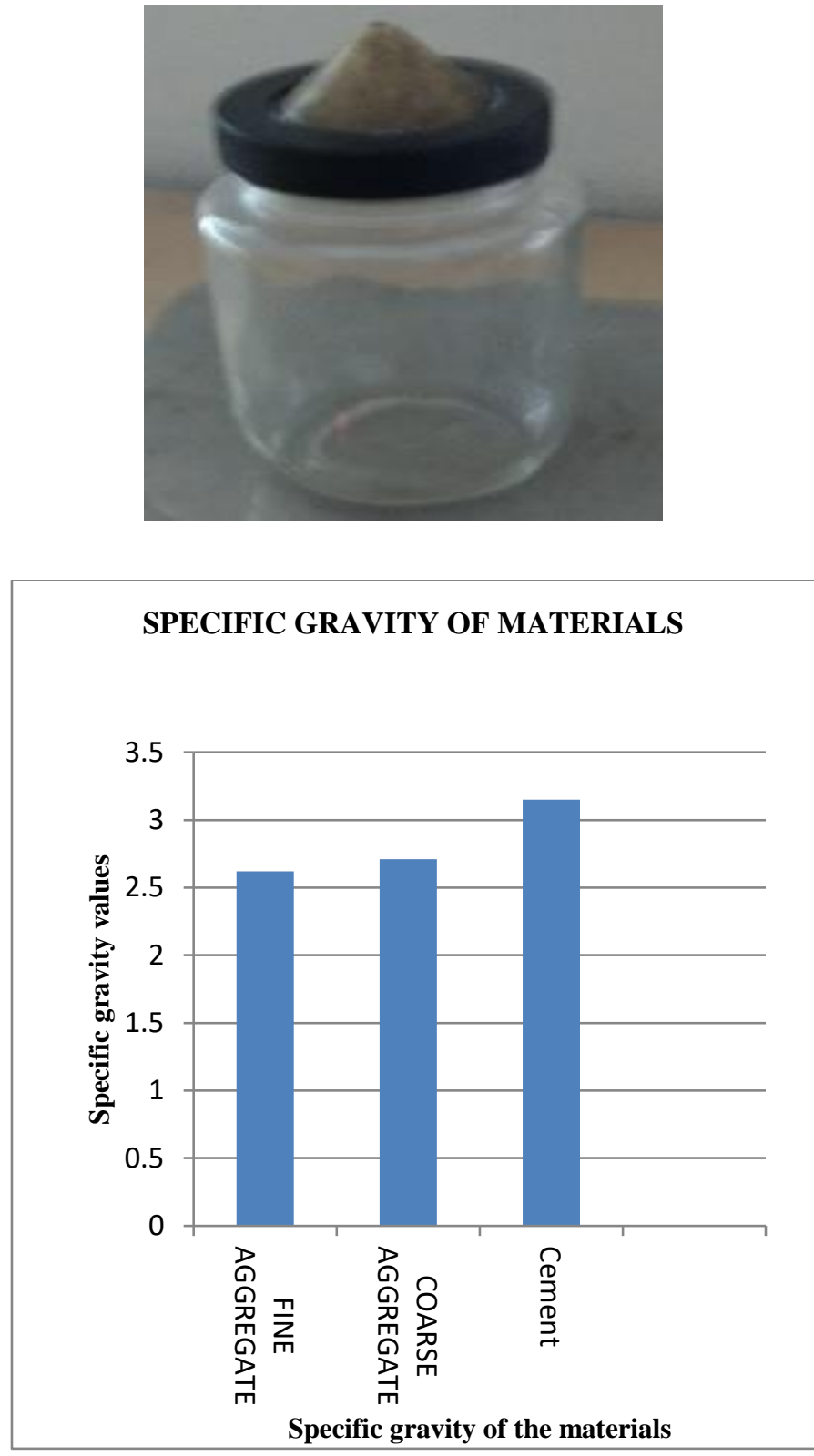

\subsection{WATER ABSORPTION TEST}

This test helps to determine the water absorption of coarse aggregates as per IS: 2386 (Part III) - 1963. For this test a sample not less than 2000g should be used.

Water absorption gives an idea of strength of aggregate. Aggregates having more water absorption 
are more porous in nature and are generally considered unsuitable unless they are found to be acceptable based on strength, impact and hardness tests.

\section{Water Absorption Test on Fine Aggregate}

Table 1. Water Absorption Test on Fine Aggregate

\begin{tabular}{|l|l|l|l|}
\hline Aggregate & I & II & III \\
\hline $\begin{array}{l}\text { Wt. Of saturated surface } \\
\text { dry aggregate (g) }\end{array}$ & 4423 & 4582 & 4776 \\
\hline $\begin{array}{l}\text { Wt. Of oven dry aggregate } \\
\text { (g) }\end{array}$ & 4375 & 4534 & 4727 \\
\hline
\end{tabular}

\section{Calculation:}

Water absorption
$\frac{\text { wt.of gat.aggregate }- \text { wt.of oven dry aggregate }}{\text { wt.of oven dry aggregate }} \times 100$

\subsection{SIEVE ANALYSIS}

A sieve analysis a practice or procedure used (commonly used in civil engineering) to assess the particle size distribution of a granular material.

The size distribution is often of critical importance to the way the material performs in use. A sieve analysis can be performed on any type of non-organic or organic granular materials including sands, crushed rock, clays, granite, feldspars, coal, and soil, a wide range of manufactured powders, grain and seeds, down to a minimum size depending on the exact method. Being such a simple technique of particle sizing, it is probably the most common.

About $1 \mathrm{~kg}$ of dry sample of fine aggregate was taken and sieved on IS sieve number: 470, 240, 60, 30 and 15. This operation was continued until number particles passed through the sieves finally. Then the material retained in each sieve was collected and weighted. The results were tabulated and the percentage of fine aggregate of varying size that passes through each sieve was calculated and recorded. The values obtained were compared with grading limit chart for fine aggregate as given in IS: 383-1970 and the actual zone, to which particular fine aggregate comes under, was determined.

Uncrushed gravel or stone which is the result of natural disintegration and crushed gravel or stone are usually called the "Coarse Aggregates". As mentioned earlier, coarse aggregates are stones that are retained on $4.75 \mathrm{~mm}$ sieve. Nearly all natural aggregates originate from bed rocks. There are three kinds of rocks, namely, igneous, sedimentary and metamorphic. In such, many properties of aggregate depend on the properties of the parent rock itself. Coarse aggregates are classified into two main groups:

1. Single size aggregate and

2. Graded aggregate.

Single size aggregate is based on a nominal size specification. It contains about 85to 100 percent of the material which passes through that specified size of the sieve and zero to $25 \%$ of which is retained in the next lower sieve. A graded aggregate contains more than one single-size aggregate. Size of the gravel affects several aspects: mainly strength \& workability. The use of largest maximum size of aggregate practicable to handle under a given set of conditions could be used. Using the largest possible maximum size will result in: reduction of the cement content, reduction in water requirement, and reduction in drying shrinkage. 

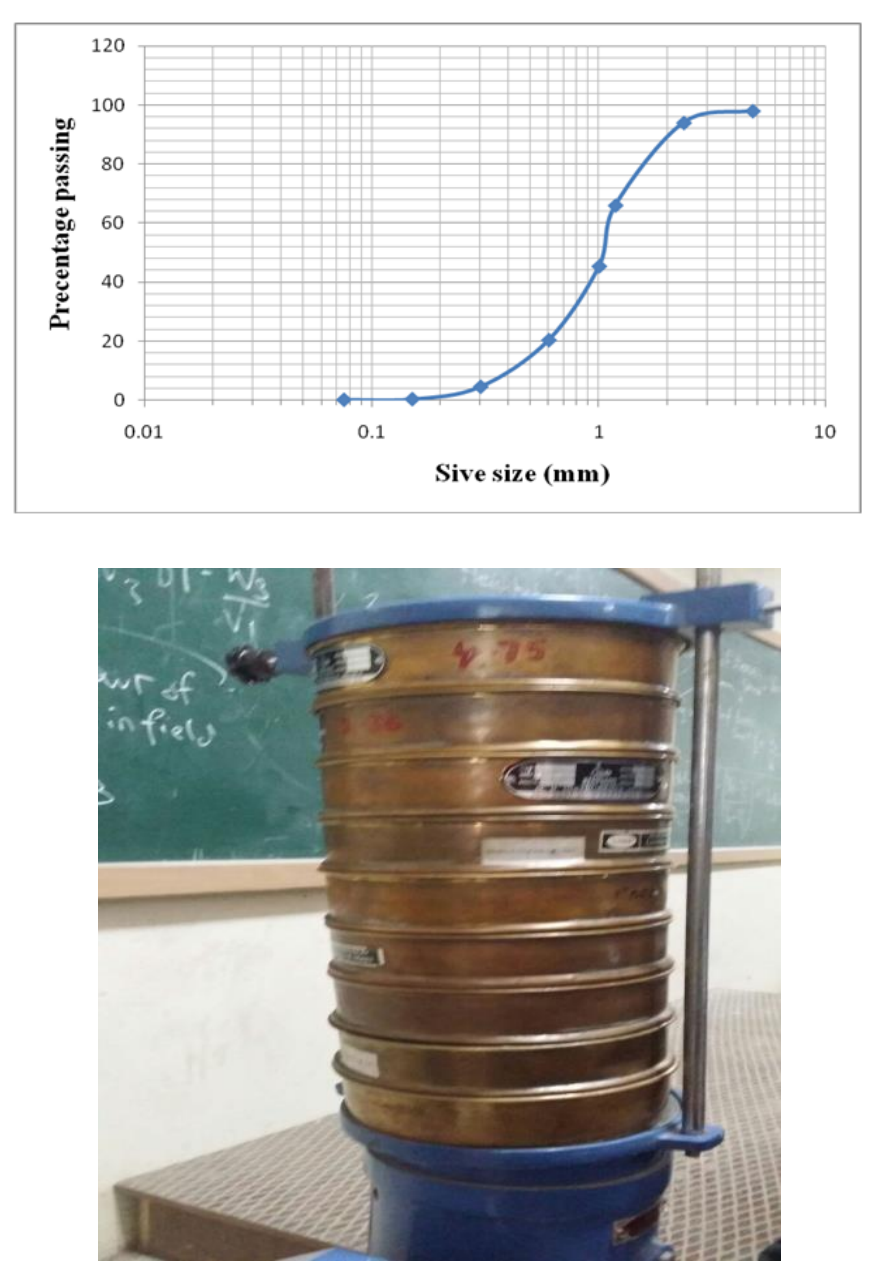

\subsubsection{Water Mould dimensions}

For casting cubes, cylinders and beams standard moulds with smooth machined inner faces were used. The inner dimensions of the cube mould were 150X150X150mm. For casting cylinders, standard cast iron mould of $150 \mathrm{~mm}$ diameter and $300 \mathrm{~mm}$ height were used. For beams $750 X 150 X 150 \mathrm{~mm}$. The mould was completely water tight during concreting.

\section{Mixing of materials}

Concrete for all the specimens were mixed by using handling equipment.

\section{Compaction}

Compaction was done through using tamping rod. The tamping was done for one third of the portion of the concrete was filled in the mould and 30 blows are made in each time.

\subsection{Test for fresh concrete}

The slump test is a measure of the behavior of a compacted cone of concrete under the action of gravity. It measures the consistency of the wetness of the concrete

\subsection{Procedure of Concrete Slump test}

- The mold for the slump test is a frustum of cone $300 \mathrm{~mm}$ of height. The base is $200 \mathrm{~mm}$ in diameter and the top is $100 \mathrm{~mm}$ in diameter.

- The base is placed on a smooth surface and the container is filled with concrete in three layers whose workability is to be tested.

- Each layer is tamped 25 times with a standard $1 \mathrm{~mm}$ diameter steel rod rounded at the end.

- When the mold is completely filled with concrete the top surface is struck off by means of screening and rolling motion of the tamping rod.

- The mold must be firmly held against its base during the entire operation that it could not move due to the pouring of concrete and this can be done by means of handles or foot rests brazed to the mould.

- Immediately after filling is completed and the concrete is leveled the cone is slowly and carefully lifted vertically an unsupported concrete will now slump.

- The decrease in the height of the center of the slumped concrete is called slump.

- The slump is measured by placing the cone just besides the slump concrete and the tamping rod is placed over the cone so that it should also come over the area of slumped concrete.

- The decrease in the height of concrete to the mould is measured with scale. The various types of slumps was shown in the figure 5.8.

- Value for M50 mix 
○ 50-90 used for normal reinforcement concrete.

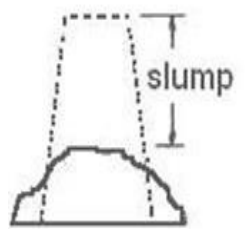

Collapse

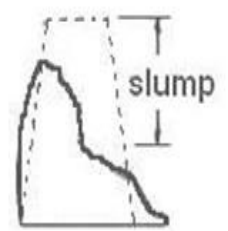

Shear

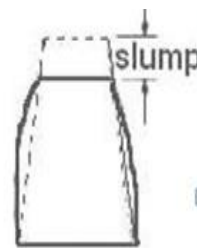

True slump

\subsection{Casting procedure and curing process}

In this study concrete of M50 grade was considered. The mix design of concrete was done. The mix proportion obtained was $1: 1.46: 2.13$ (cement,sand, coarse aggregate, water) the mix design gives the cement content of $475 \mathrm{~kg} / \mathrm{m} 3$ of concrete.

Using the above mix proportion, a total number of 30 standard concrete specimens are 150X150X150 mm size of cubes and 30 number of cylinders specimens are having size of $150 \mathrm{~mm}$ diameter, $300 \mathrm{~mm}$ height and 10 number of beam specimens are having size of 700X150X150 mm. The number of cubes and cylinders are casted 30 for dry curing or kept as dry 30 for water curing and the number of beams are casted 5 for dry curing and 5 for water curing.

Cast iron moulds are used for casting. For casting specimen, three different proportion in fraction of Super absorbent polymer are $0 \%, 0.2 \%, 0.3 \%, 0.4 \%$ and $0.5 \%$. The concrete was mixed by manually and then it was poured in to the moulds in layer by layer. Compaction was done by a tamping rod. The specimens were removed after 24 hours of casting and then cured under water for 7 days and 28 days. The specimens were taken out from the curing tank and dried itself of 24 hours before the period of testing

\subsection{COMPRESSIVE STRENGTH TEST}

The cubes are casted according to the design, then after setting of concrete, demould the cube. Then take them to the curing pit and place the cubes in it for 7 days and 28 days. Take the cubes out and wipe them and place it under dry condition for 2-3 hours. The cubes are tested in compression testing machine.

The compressive strength is the capacity of a material or structure to withstand loads tending to reduce size. It can be measured by plotting applied force against deformation in a testing machine. Some materials fracture at their compressive strength limit; others deform irreversibly, so a given amount of deformation may be considered as the limit for compressive load. Compressive is a key value for design of structures. This test is done to determine the compressive strength of concrete as per IS 5161959 (Methods of tests for strength of concrete).

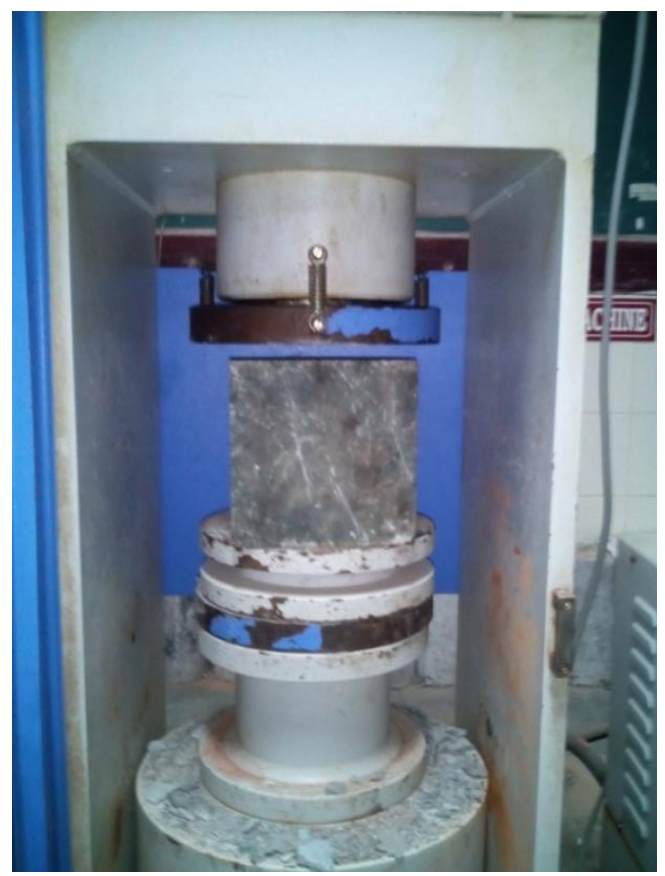

Fig 4.9.1 Testing of Compressive Strength of Cube

Compressive strength is often measured on a universal testing machine; these range from very small table-top systems to ones with over $53 \mathrm{MN}$ capacity Measurements of compressive strength are 
affected by the specific test method and conditions of measurement. Compressive strengths are usually reported in relationship to a specific technical standard.

\section{CALCULATION:}

Compressive strength in $\mathrm{N} / \mathrm{mm}^{2}=\frac{\text { Load }}{\text { Area }}$

\subsection{SPLIT TENSILE STRENGTH TEST :}

For the determination of splitting tensile strength of concrete, cylinder specimens of diameter to length ratio 1:2 was selected, with diameter as $150 \mathrm{~mm}$ and the length as $300 \mathrm{~mm}$ specimens were dried in open air after 7 days and 28 days of curing and subjected to splitting tensile test under universal testing machine. The rate of loading was adjusted as 0.11 to 0.023 $\mathrm{MPa} / \mathrm{sec}$ as per ASTM C496-90. While testing the specimens, plywood pieces one at the top and the other at the bottom. The split tensile strength (f) was obtained using the formula

\section{$\mathrm{F}=2 \mathrm{P} / 3.14 \mathrm{dl}\left(\mathrm{N} / \mathrm{mm}^{2}\right)$}

Where $\mathrm{P}=$ load at failure $(\mathrm{N})$,

$\mathrm{d}=$ diameter of specimen $(\mathrm{mm})$,

$\mathrm{l}=$ length of specimen $(\mathrm{mm})$

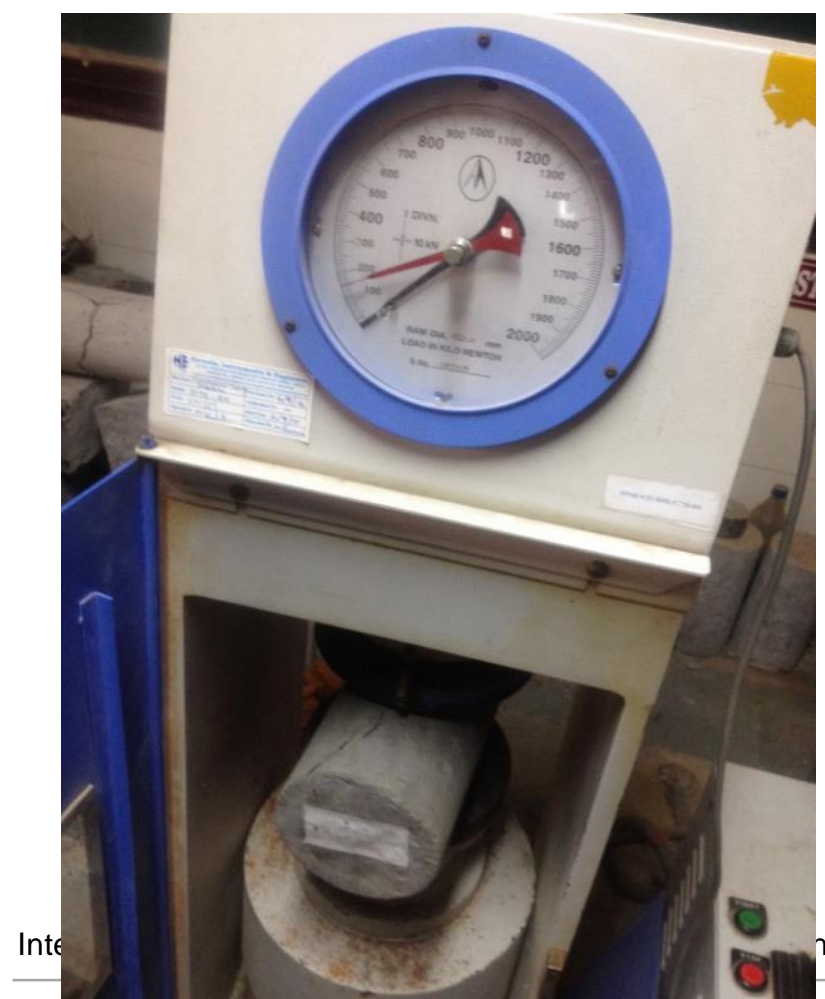
after 7 days for air dry and 7 days for Water curing

\section{v. CONCLUSION}

Fig.1.10.2. Bar graph for tensile strength of cylindres
7 DAYS

STRENGTH FOR

AIR DRY

7 DAYS

STRENGTH FOR

WATER CURING

Column1
STRENGTH

28 DAYS

of 7 days and 28 days for Air dry

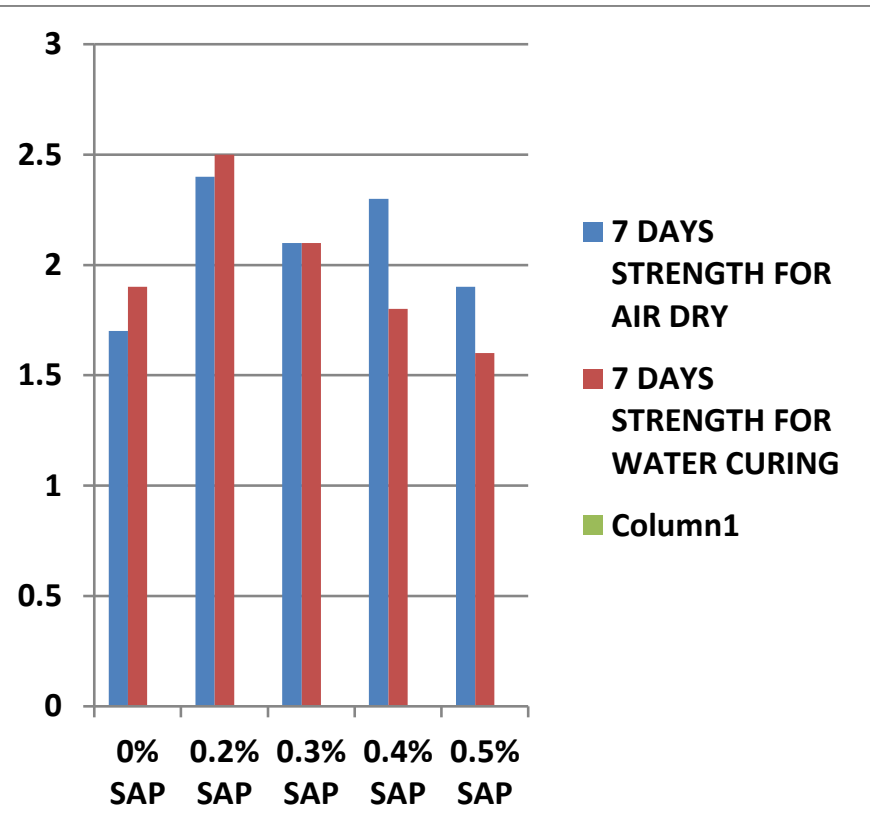


The internal curing (IC) or self curing by the addition of silica fume is an effective means of drastically reducing autogenous shrinkage. Since autogenous shrinkage is a main contributor to early-age cracking, it is expected that IC would also reduce such cracking. An additional benefit of IC beyond autogenous shrinkage reduction is increase in compressive strength. As internal curing maintains saturated conditions within the hydrating cement paste, the magnitude of internal self-desiccation stresses are reduced and long term hydration is increased. IC is particularly effective for the high performance concretes containing silica fume.

- Water retention for the concrete mixes incorporating self-curing agent is higher compared to conventional concrete mixes, as found by the weight loss with time.

- The optimum dosage is $0.2 \%$.Addition of SAP leads to a significant increase of mechanical strength (Compressive and Splitting tensile).

- Compressive strength of self-cured concrete for dosage of $0.2 \%$ was higher than water cured concrete for 7 days testing.

- Split tensile strength of self-cured concrete for dosage of $0.2 \%$ was higher than water cured concrete for 7 days testing.

- Flexural strength of self-cured concrete for dosage of $0.2 \%$ and $0.3 \%$ was higher.

- There was a gradual increase in the strength for dosage from $0 \%$ to $0.2 \%$ and later gradually reduced.

- The Self-cured concrete using SAP was more economical than conventional cured concrete.

- In the study cubes,cylinders and beams were casted and kept for air dry and water curing in room temperature about 250-300c.practical feasibility of self cured member is need to be checked in hot regions.

\section{REFERENCES}

[1]. Jensen, O., and Hensen, "Autogenous deformation and RH-Change in prospective," Cement and Concrete Research, Vol. 31, No. 12 ,

[2]. Dec. 2001, pages 1859-1865.

[3]. Al-Nasra, Moayyad, "Optimizing the Use of Sodium Polyacrylate in Plain Concrete," International Journal of Engineering Research and Applications (IJERA) ISSN: 22489622 www.ijera.com, Vol. 3, Issue 3, May-Jun 2013, pages 1058-1062.

[4]. Hwang D-C, Damodaran S, Metal-chelating properties and biodegradability of an ethylenediamine tetraacetic acid dianhydride modified soy protein hydrogel, J Appl Polym Sci, 64, 891-901, 1997.

[5]. Damodaran S, Hwang D-C, Carboxyl-modified superabsorbent protein hydrogel, US Patents 5,847,089, 1998.

[6]. Hasholt, M.T.; Jespersen, M.H.S.; and Jensen, O.M., "Mechanical Properties of Concrete with SAP Part I: Development of Compressive Strength," International RILEM Conference on Use of Superabsorbent Polymers and Other New Additives in Concrete, O.M. Jensen, M.T. Has

\section{Cite this article as :}

V. Veera Mohan Reddy, K. Mohammed Rasheed, "An Experimental Investigation on the Strength Properties of Self Curing Concrete by Using Super Absorbrnt Polymer", International Journal of Scientific Research in Science and Technology (IJSRST), Online ISSN : 2395-602X, Print ISSN : 2395-6011, Volume 6 Issue 2, pp. 634-643, MarchApril 2019. Available at doi : https://doi.org/10.32628/IJSRST1962135 Journal URL : http://ijsrst.com/IJSRST1962135 